\title{
Quantitative Determination of Lipase Activity by Liquid Chromatography-Mass Spectrometry
}

\author{
Gang Hao, Lan Yang, Istvan Mazsaroff, and Melanie Lin \\ Altus Pharmaceuticals, Cambridge, Massachusetts, USA
}

We developed a novel in vitro lipase assay based on the quantitation of fatty acids by liquid chromatography-mass spectrometry. Oleic acids enzymatically released from triolein substrates were isolated from the reaction mixture by reverse-phase chromatography, ionized in negative mode electrospray mass spectrometry and quantitated with the aid of $\left[{ }^{13} \mathrm{C}\right]$-oleic acid internal standard. The enzymatic activity was measured by monitoring oleic acid productions at multiple time points. This method overcomes the substrate and $\mathrm{pH}$ limitations of conventional techniques and thus serves as a generic lipase activity assay. (J Am Soc Mass Spectrom 2007, 18, 1579-1581) (c) 2007 American Society for Mass Spectrometry

L ipases are ubiquitous enzymes that catalyze the hydrolysis of triacylglycerols (TAGs), releasing long-chain fatty acids in a site-specific manner [1]. Lipases are involved in diverse biological processes ranging from fat metabolism to cell signaling and inflammation [2-4]. Lipases also serve as treatment for disorders including pancreatic insufficiency, Celiac disease and cystic fibrosis [5-7]. In addition to their therapeutic uses, these enzymes have important applications in the food, cosmetics and environmental industries [8]. Numerous assays are available for determining lipolytic activity, monitoring the disappearance of TAG, or the release of fatty acid and glycerol $[9,10]$. It is notable that in the excess of substrate, a mixture of mono-, 1 , 2/1, 3 diacylglycerol and glycerol are formed, and the enzyme has different activities towards mono-, di-, and triacylglycerol [11]. Hence, monitoring the release of fatty acid is the most direct approach to determine lipase activity.

The existing methods targeting fatty acids require radioactive- or fluorescence-labeled TAGs for detection [12-15]. Another widely-used assay is based on the titration of $\mathrm{pH}$ drop associated with fatty acid formation [16], but is restricted to higher $\mathrm{pH}$ levels. For these reasons, we sought to develop a method that was compatible with native TAG substrates in a broad $\mathrm{pH}$ range. Mass spectrometry is a powerful tool for lipid analysis [17]. Fatty acids have been characterized by gas chromatography-mass spectrometry (GC-MS) and liquid chromatography-mass spectrometry (LC-MS) [18, 19]..$^{\circ} \mathrm{In}^{\circ}$ this $^{\circ}$ study, ${ }^{\circ}$ we ${ }^{\circ}$ investigated ${ }^{\circ}$ the ${ }^{\circ}$ quantitative aspect of LC-MS for fatty acid analysis and its applicability as an activity assay. We demonstrated that LC-MS

Address reprint requests to Dr. G. Hao, Altus Pharmaceuticals, 195 Albany Street, Cambridge, MA 02139, USA. E-mail: ghao@altus.com provides a simple, specific, and sensitive method for determining lipase activity.

\section{Materials and Methods}

\section{Materials}

Triolein and oleic acid were purchased from SigmaAldrich (St. Louis, MO); $\left[{ }^{13} \mathrm{C}\right]$-oleic acid was obtained from Spectra Stable Isotopes (Columbia, MD); HPLCgrade water, methanol, and 1-propanol were from Fisher (Fair Lawn, NJ). Microbial lipase was produced by Altus Pharmaceuticals (Cambridge, MA).

\section{Lipase Assay}

Twenty $\mathrm{mM}$ triolein substrate solution was prepared by dissolving triolein into a solution containing $20 \%$ Triton X-100 and a $100 \mathrm{mM}$ amino acid buffer (histidine, glycine and glutamate) at $\mathrm{pH}$ 6.0; the buffer may be adjusted to other $\mathrm{pH}$ levels for additional assays. To initiate the enzymatic reaction, $0.02 \mu \mathrm{g}$ lipase was added to $1 \mathrm{~mL}$ of the substrate solution and the reaction mixture was incubated at $37^{\circ} \mathrm{C}$ with gentle agitation. Samples of $2 \mu \mathrm{L}$ of the reaction mixture were taken at time points $0,2,5,10$, and $15 \mathrm{~min}$, and diluted 500-fold with methanol containing $10 \mu \mathrm{M}\left[{ }^{13} \mathrm{C}\right]$-oleic acid. Oleic acid concentrations measured by LC-MS were plotted versus reaction time to determine activity.

\section{Quantitation of Oleic Acid by LC-MS}

Two $\mu \mathrm{L}$ of the diluted reaction mixture were injected into a LC-MS system comprised of a capillary LC (Agilent, Palo Alto, CA), coupled via electrospray to a Micromass quadrupole-time-of-flight (Q-TOF) mass spectrometer (Waters, Milford, MA). The lipids were resolved 
on a $0.3 \times 150 \mathrm{~mm}$ ZORBAX C18 column (Agilent) at a flow rate of $10 \mu \mathrm{L} / \mathrm{min}$. The column was equilibrated with solvent A (95\% methanol, 5\% 1-propanol). Solvent B (20\% methanol, $80 \%$ 1-propanol) was increased from 5\% to $15 \%$ at $9 \mathrm{~min}$, then to $40 \%$ at $10 \mathrm{~min}$ until $15 \mathrm{~min}$. The mass spectra were collected in negative ion mode from 150 to $400 \mathrm{~m} / \mathrm{z}$. The capillary voltage was $2500 \mathrm{~V}$, the cone voltage was $35 \mathrm{~V}$, the source temperature was $80^{\circ} \mathrm{C}$, and the collision energy was $10 \mathrm{~V}$. After data acquisition, an extracted ion chromatogram was generated for oleic acid and the internal standard at $\mathrm{m} / \mathrm{z}$ of 281.25 and 299.25, respectively. Peak integration was performed by MassLynx program (version 4.0, Waters) and fatty acid concentrations were calculated from the relative peak areas.

\section{Results and Discussion}

We selected triolein (2, 3-bis[\{(E)-octadec-9-enoyl\}oxy $]$ propyl (E)-octadec-9-enoate), the major component of dietary oil, as the substrate for lipase reaction and monitored the release of oleic acid [(Z)-octadec-9-enoic acid]. Before the reaction, triolein was emulsified in Triton $\mathrm{X}$ to ensure sample homogeneity. We reasoned that the deprotonation of oleic acid rendered it detectable in negative mode mass spectrometry, whereas triolein $^{\circ}$ and $^{\circ}$ Triton $^{\circ} \mathrm{X}^{\circ}$ should $^{\circ}$ not $^{\circ}$ ionize. $^{\circ}$ Figure $^{\circ}$ 1a depicts the negative mode mass spectrum of equal concentration of native and $\left[{ }^{13} \mathrm{C}\right]$-oleic acid. The observed $\mathrm{m} / \mathrm{z}$ at 281.25 and 299.25 Da were in agreement with the predicted $\mathrm{m} / \mathrm{z}$ of native and $\left[{ }^{13} \mathrm{C}\right]$-oleic acid anions, respectively. Despite the selectivity afforded by negative mode MS, triolein and Triton $X$ presented in much greater concentrations that might interfere with fatty acid ionization. We employed a reverse phasegradient with methanol and 1-propanol mobile phases to isolate oleic acid from the rest of the reaction mixture (see ${ }^{\circ}$ the ${ }^{\circ}$ Methods ${ }^{\circ}$ section). ${ }^{\circ} \mathrm{As}^{\circ}$ shown $^{\circ}$ in ${ }^{\circ}$ Figure $1 \mathrm{~b}$, ${ }^{\circ}$ oleic acid eluted around $6 \mathrm{~min}$, slightly after the Triton $X$ peak, which was identified by its characteristic ion clusters (data not shown). The intensity of the Triton $X$ peak was significantly lower than its positive mode counterpart, which indicated only a fraction of Triton $\mathrm{X}$ underwent deprotonation. Triolein was not detected in negative mode electrospray-mass spectrometry (ESIMS). Its elution time was around $12 \mathrm{~min}$, monitored as an ammonium adduct in positive mode MS (data not shown). These results demonstrated that the LC method completely resolved oleic acid from other major components in the assay mixture.

We then examined the linearity and sensitivity of LC-MS quantitation. A dilution series of oleic acid prepared in the substrate solution were mixed with internal standards and analyzed by LC-MS. The extracted ion chromatogram peak at $281.25 \mathrm{~m} / \mathrm{z}$ (oleic acid) and $299.25 \mathrm{~m} / \mathrm{z}$ (internal standard) were integrated and the peak area ratio (oleic acid/internal standard) was plotted against the corresponding concentration ratio to generate ${ }^{\circ}{ }^{\circ}$ calibration $^{\circ}$ curve $^{\circ}$ As $^{\circ}$ shown $^{\circ}{ }^{\circ}{ }^{\circ}$ Pigure $^{\circ} 2$, the
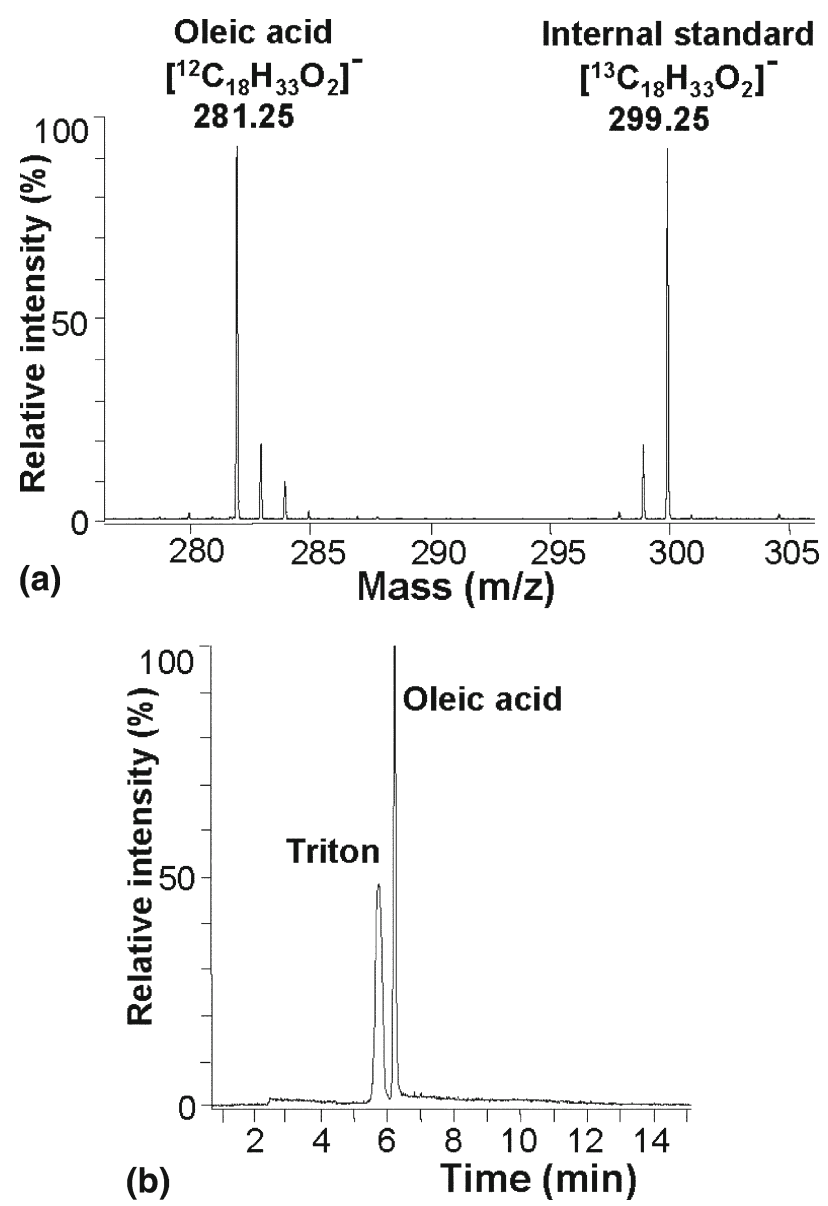

Figure 1. Separation and detection of oleic acid by LC-MS. Oleic acid generated from triolein was resolved from triolein and Triton $X$ in the reaction mixture by reverse phase LC and detected in negative mode ESI-MS. (a) The total ion chromatography of the reaction mixture. Oleic acid was completely resolved from Triton $X$. Triolein was undetected in negative mode ESI-MS and its eluted around $10 \mathrm{~min}$, monitored by positive mode ESI-MS in a separate experiment. (b) Negative mode ESI-MS mass spectrum of oleic acid and $\left[{ }^{13} \mathrm{C}\right]$-oleic acid (internal standard). Oleic acid was detected as deprotonated ion in negative mode ESI-MS. The observed $m / z$ at 281.25 and 299.25 is in agreement with the theoretical $\mathrm{m} / \mathrm{z}$.

standard curve has a linear range extended about three orders of magnitude, ranging from $0.5 \mu \mathrm{M}$ to $0.2 \mathrm{mM}$. The limit of quantitation was 1 pmol at 10:1 signal to noise ratio, which is sufficient for most in vitro lipase assays.

We applied this method to measure the activity of a microbial lipase. The lipase had a low millimolar $\mathrm{Km}$, and we used $20 \mathrm{mM}$ triolein to reach at least $5 \mathrm{Km}$ for the activity assay. The enzyme amount was optimized to allow the concentration of produced fatty acid to fall into the linear range of quantitation. We routinely performed assays from $\mathrm{pH} 5$ to $\mathrm{pH} 7$; only the data from $\mathrm{pH} 6$ is shown here. Samples of $\mu \mathrm{L}$ of the reaction mixture were taken at each time points of $0,2,510$, and $15 \mathrm{~min}$ and diluted with methanol to terminate the digestion (see the Methods section). We found that methanol dilution completely abolished the enzymatic 

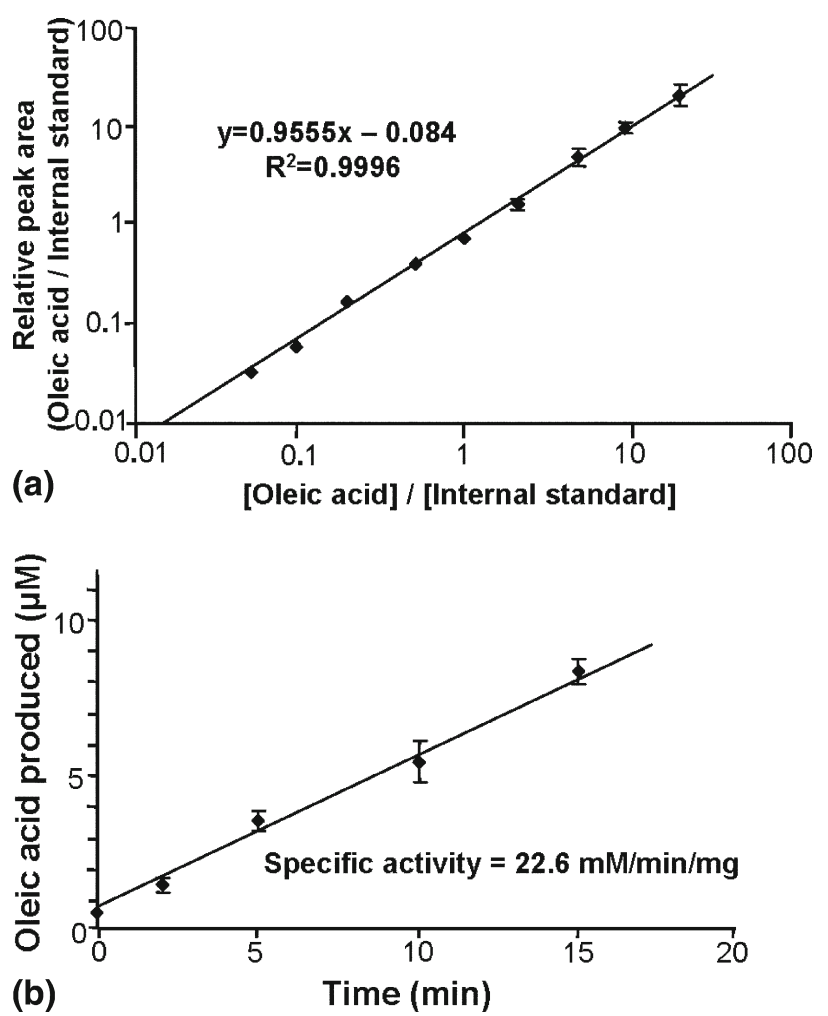

Figure 2. Assay the activity of lipase from microbial lipase by LC-MS. (a) A standard curve revealed a linear detection response from 0.5 to $200 \mu \mathrm{M}$. A dilution series of oleic acid were prepared in the substrate solution containing $10 \mu \mathrm{M}\left[{ }^{13} \mathrm{C}\right]$-oleic acid. The peak area ratio of oleic acid versus internal standard was plotted against the corresponding concentration ratio. The limit of quantitation was 1 pmol; values are means \pm SE of three replicate determinations. (b) Assay the activity of microbial lipase by quantitation of oleic acid concentrations at multiple reaction time points; $0.02 \mu \mathrm{g}$ lipase was incubated with $1 \mathrm{~mL}$ substrate solution at $37^{\circ} \mathrm{C}$. At indicated time points, $2 \mu \mathrm{L}$ of the reaction mixture was diluted with methanol containing $10 \mu \mathrm{M}$ internal standard, and analyzed by LC-MS. Values are means \pm SE of three replicate determinations.

activity (data not shown). $\left[{ }^{13} \mathrm{C}\right]$-oleic acid was added at a final concentration of $10 \mu \mathrm{M}$ and the fatty acid in the reaction mixture was quantitated by LC-MS as described ${ }^{\circ}$ above. ${ }^{\circ}$ Figure ${ }^{\circ} 2 b^{\circ}$ depicts $^{\circ}$ the ${ }^{\circ}$ enzymatic ${ }^{\circ}$ kinetic curve generated by plotting Oleic acid concentrations versus the reaction time. The curve reveals that the initial velocity remained constant during the initial phase of the reaction. At time zero, there was a certain amount of fatty acid produced, which apparently originated from self-hydrolyzing triolein. Hence, triolein solutions must be freshly prepared from frozen stocks to minimize the assay background. In the case of the experimental sample, the specific activity calculated from the slope of the reaction curve was $22.6 \mathrm{mM}$ / $\mathrm{min} / \mathrm{mg}(22,600 \mathrm{U} / \mathrm{mg})$.
In the LC-MS method, the detection and quantitation step was completely independent of the lipolytic reaction. Therefore, the assay was compatible with various detergents, substrates and $\mathrm{pH}$. The internal standard was not absolutely required, as it only afforded modest improvement in quantitation at higher concentrations, where the Q-TOF detector began to saturate. Mass spectrometry instruments with greater dynamic range, e.g., quadrupole MS, should eliminate the need for internal standards. The method had low samples throughout due to the noncontinuous nature. Nonetheless, the assay time could be shortened by reducing the chromatography time. We believed that this assay provides a significantly improved analysis for lipase activities in a variety of biological systems.

\section{References}

1. Dakin, H. D. The hydrolysis of optically inactive esters by means of enzymes: Part I. The action of lipase upon esters of mandelic acid. The resolution of inactive mandelic acid. J. Physiol. 1903, 30, 253-263.

2. Mu, H.; Porsgaard, T. The metabolism of structured triacylglycerols. Prog. Lipid Res. 2005, 44, 430-448.

3. Spiegel, S.; Foster, D.; Kolesnick, R. Signal transduction through lipid second messengers. Curr. Opin. Cell. Biol. 1996, 8, 159-167.

4. Paradis, M.-E.; Badellino, K. O.; Rader, D. J.; Deshaies, Y.; Couture, P.; Archer, W. R.; Bergeron, N.; Lamarche, B. Endothelial lipase is associated with inflammation in humans. J. Lipid Res. 2006, 47, 2808-2813.

5. Layer, P.; Keller, J.; Lankisch, P. G. Pancreatic enzyme replacement therapy. Curr. Gastroenterol. Rep. 2001, 3, 101-108.

6. Carroccio, A.; Iacono, G.; Montalto, G. Pancreatic enzyme therapy in childhood celiac disease. A double-blind prospective randomized study. Dig. Dis. Sci. 1995, 40, 2555-2560.

7. Brady, M. S.; Garson, J. L.; Krug, S. K.; Kaul, A.; Richard, K. A.; Caffrey, H. H.; Fineberg, N.; Balistreri, W. F.; Stevens, J. C. An enteric-coated high-buffered pancrelipase reduces steatorrhea in patients with cystic fibrosis: A prospective, randomized study. J. Am. Diet Assoc. 2006, 106, 1181-1186.

8. Schmid, R. D.; Verger, R. Lipases: Interfacial enzymes with attractive applications. Angew. Chem. Int. Ed. 1998, 37, 1608-1633.

9. Beisson, F.; Tiss, A.; Rivière, C.; Verger, R. Methods for lipase detection and assay: A critical review. Eur. J. Lipid Sci. Technol. 2000, 102, 133-153.

10. Schmidt, M.; Bornscheuer, U. T. High-throughput assays for lipases and esterases. Biomol. Eng. 2005, 22, 51-66.

11. Frazer, A. C.; Sammons, H. G. The formation of mono- and diglycerides during the hydrolysis of triglyceride by pancreatic lipase. Biochem. J. 1945, 39, 122-128.

12. Hills, M. J.; Mukherjee, K. D. Assay for triacylglycerol lipase by a rapid thin-layer chromatographic technique. J. Lipid Res. 1988, 29, 1397-1399.

13. Briquet-Laugier, V.; Ben-Zeev, O.; Doolittle, M. H. Determining lipoprotein lipase and hepatic lipase activity using radiolabeled substrates. Methods Mol. Biol. 1999, 109, 81-94.

14. Duque, M.; Graupner, M.; Stütz, H.; Wicher, I.; Zechner, R.; Paltauf, F.; Hermetter, A. New fluorogenic triacylglycerol analogs as substrates for the determination and chiral discrimination of lipase activities. J. Lipid Res. 1996, 37, 868-876.

15. Hendrickson, H. S. Fluorescence-based assays of lipases, phospholipases, and other lipolytic enzymes-a review. Anal. Biochem. 1994, 219, 1-8.

16. Brockman, H. L. Triglyceride lipase from porcine pancreas. Methods Enzymol. 1981, 71, 619-627.

17. Isaac, G.; Jeannotte, R.; Esch, S. W.; Welti. R. New mass-spectrometrybased strategies for lipids. Genet. Eng. (NY). 2007, 28, 129-157.

18. Byss, M.; Triska, J.; Elhottova, D. GC-MS-MS analysis of bacterial fatty acids in heavily creosote-contaminated soil samples. Anal. Bioanal. Chem. 2007, in press.

19. Lee, S. H.; Pettinella, C.; Blair, I. A. LC/ESI/MS analysis of saturated and unsaturated fatty acids in rat intestinal epithelial cells. Curr. Drug Metab. 2006, 7, 929-937. 